\title{
Evaluating TESL Students' Beliefs about Foreign Language Learning
}

\author{
Zailani Jusoh ${ }^{1}$ \\ ${ }^{1}$ Faculty of Languages and Communication, Universiti Sultan Zainal Abidin, Malaysia \\ Correspondence: Zailani Jusoh, Faculty of Languages and Communication, Universiti Sultan Zainal Abidin, \\ Kuala Nerus, Terengganu, Malaysia. E-mail: zailani@unisza.edu.my
}

Received: June 12, 2017 Accepted: July 10, 2017 Online Published: October 11, 2017

doi:10.5539/ijel.v7n6p228 URL: http://doi.org/10.5539/ijel.v7n6p228

\begin{abstract}
Learning a foreign language is a monumental undertaking for many adult learners. This study was conducted to mainly explore university students' beliefs about foreign language learning. It was also to investigate whether differences in their beliefs were present among different foreign languages. Students, pursuing diploma in TESL in a public university in Malaysia, were chosen as respondents. An instrument, BALLI, which is a measure of students' beliefs about language learning was the primary instrument for data collection. Since this is a quantitative study, statistical techniques namely descriptive and a one-way ANOVA were employed. Findings indicate that generally, the beliefs held by the student teachers are positive. Nonetheless, significant differences in the beliefs were noted among the foreign languages. The findings have a number of pedagogical implications. One of which is the importance of instilling realistic beliefs among students in learning foreign languages.
\end{abstract}

Keywords: BALLI, student teachers, foreign languages, ANOVA, university students

\section{Introduction}

As the world is becoming borderless, the need to be conversant in more than one language has never been more pressing than at present. Currently, the most popular second language is English as it is spoken and understood by at least 1.5 billion people worldwide of which 1.1 billion use it as additional language (www.statistica.com). However, with the emergence of new economic super powers such as China and India, knowledge in the English language alone is insufficient to cope with the constantly changing demand of workplace. Thus, this has given rise to learning other foreign languages such as Mandarin, Japanese and Hindi.

\subsection{Language Learning in Malaysia}

Since independence, language education has always played important roles in the national education system. Bahasa Malaysia, being the official language of the country and the lingua franca in this region, is the medium of instruction in all national schools and taught as a subject in vernacular schools. Another language that is equally emphasized in school is English. As a former British colony, Malaysia has always recognised the position of English as a second language (ESL). It is widely used in commercial and international sectors. Additionally, by virtue of its racial diversity, minority group languages such as Chinese and Tamil are also "treasured" as these languages are spoken by its community and are used as the medium of instruction in vernacular schools.

With regard to language policy in the education system, English was previously the only additional language made compulsory to students in all schools. Nonetheless, the ever changing landscape of the society has forced the government to respond accordingly by introducing a new policy pertaining to foreign language learning. In fact this has been highlighted in the National Higher Education strategic plan beyond 2020. The strategic plan stresses that "proficiency in the third language is vital for developing human capital that drives the k economy as well as gears towards competitive innovation in the international area" (MOHE, 2007, p. 62). This has once again been reiterated in the recently released National Education Blueprint 2013-2025 which states that

the aspiration of the education system is to create students that are at least operationally proficient in both Bahasa Malaysia and English. All students will also be encouraged to learn an additional language to independent proficiency. It is hoped that by 2025 , at least $30 \%$ students achieve independent proficiency in an additional language. (p. 108)

In line with this aspiration, many institutions of higher learning have begun to introduce foreign languages. In fact, some universities have even included foreign languages in their curriculum by making it mandatory for all 
students to enroll in at least one foreign language class in addition to English as graduation requirements. Among foreign languages commonly offered are Mandarin, French, Arabic and Japanese.

Regardless of the efforts by the government and its agencies in encouraging students to learn an additional language, it is not likely to produce much impact on students' language performance if fundamental issues are not addressed fully. One of these issues includes understanding students' affective domain such as attitudes, motivation and beliefs towards a foreign language. They play important roles in the success of language learning. This is because language learning is different from learning subject matter such as science and mathematics since it involves more intricate processes. As Horwitz (1987) posits "foreign language learning demands a level of personal engagement unlike that of any other subject matter studied in academic settings" (p. 573). Thus, there is a need to understand about students' perspectives on language learning in order to create a more conducive environment.

Undoubtedly, there is a growing interest in understanding the influence of beliefs in learning languages. However, most of the studies were conducted in the context of learning English either as a second or foreign language (Bernat, 2006; Peacock, 2001). Not much has been done to investigate the beliefs when it comes to learning foreign languages such as Japanese, Thai or Mandarin. Although learning a language, be it English, Arabic or Spanish, shares similarities, the fact that when the language is learnt as a foreign language invokes different emotional uncertainty for the lack of opportunity to use the language (Brown, 2000).

Thus, studies understanding students' beliefs when learning a foreign language should be undertaken as "learners' beliefs and expectations of language learning may enhance or slow down the process" (Weideman \& Lepota, 2002, p. 48). If students have positive beliefs and attitude about a particular language, learning the language will be more enjoyable and less stressful. On the contrary, if they have misconceptions about a language, this may influence the way the language is learnt. This will in turn, impact the whole learning process negatively.

\subsection{Bandura's Social Cognitive Theory}

The concept of beliefs stems from Bandura's Social Cognitive Theory which emphasises on the idea that humans are "self-organizing, self-regulating, proactive, and self-reflecting in shaping their own learning and behavior" (Pajares, 2002, p. 14). The theory also recognises the interactive influences the person, behaviour and environment have on individuals. In other words, it suggests that individual's behaviour is determined by the interaction between personal and environmental factors. Personal factors such as beliefs, influence behaviour and they are developed from our environment. There is also a tendency for the individual to be engaged in activities in which he/she believes he/she is capable of doing while at the same time avoiding those he/she is not confident of performing. Because these beliefs determine how people feel, think and behave, they are considered powerful determinant of behaviour compared to the actual ability. These beliefs shape people's behaviour in many occasions.

\subsection{Beliefs and Language Performance}

Research on the beliefs about language learning has shown that beliefs held by learners have great influence on language performance. These influences can either have supportive or damaging effects on their learning. However, most of the studies conducted investigated the beliefs among those in English as a second language context. These include Peacock (2001) who reports on a longitudinal study that investigated changes in the beliefs about second language learning of 146 trainee ESL students over their 3-year program at the City University of Hong Kong. Although he reports differences in three key areas, disturbingly, no significant changes have been found. These key areas are: learning a second language means learning a lot of vocabulary and grammar rules and the belief that those speaking more than one language well are very intelligent.

Studies comparing the differences among foreign languages other than English are not as widely conducted. Those who have carried out the studies have reported mixed results. For example, Ariogul, Cigdem, \& Onursal, (2009) compared English, German, and French language learners and found that certain language learners had better expectations in language learning and learners of some language were reported having beliefs that were detrimental to their learning. Another study, Altan (2006) was conducted on 436 English, French, German, Arabic, and Japanese pre-service language teachers in Turkey which produced different results. The findings of this study suggested that there is a significant similarity among the responses given by all groups except a few items that are slightly different from each other.

In the context of Malaysia, although a number of studies have been conducted investing hating language learning beliefs (Wong, 2010), most of them focused on English as a second language. Not much has been done to investigate foreign language beliefs among the Malaysians. Nikitina \& Furuoka (2007), though study beliefs 
among learners of Russia, were more focused on comparing the beliefs held by the students at different proficiency levels instead of investigating the beliefs among different languages.

\section{Method}

The following section describes the methodology employed in this study.

\subsection{Instrumentation}

The instrument, BALLI (Beliefs about Language Learning Inventory) developed by Horwitz (1987) was the primary instrument used in data collection. The instrument consists of 34 items, which were mostly rated on a five point Likert scale from strongly disagree (1) to strongly agree (5). Two items (item 4 and 15), however were rated differently. They are presented in Table 1 below.

Table 1. Items with different responses

\begin{tabular}{|c|c|c|c|}
\hline item & statement & rating & category \\
\hline item 4 & I think this language is ___ to learn & $\begin{array}{l}5 \text { very difficult } \\
4 \text { difficult } \\
3 \text { medium difficulty } \\
2 \text { easy } \\
1 \text { very easy }\end{array}$ & $\begin{array}{l}\text { belief about difficulty of } \\
\text { language learning }\end{array}$ \\
\hline item 15 & $\begin{array}{l}\text { If someone spend an hour a day } \\
\text { learning a language, it will take them } \\
\text { to speak the language fluently }\end{array}$ & $\begin{array}{l}5 \text { cannot learn in an hour a day } \\
45-10 \text { years } \\
3 \text { 3-5 years } \\
2 \text { 1-2 years } \\
1 \text { less than a year }\end{array}$ & $\begin{array}{l}\text { belief about difficulty of } \\
\text { language learning }\end{array}$ \\
\hline
\end{tabular}

Additionally, slight modifications were made to the original instrument as the word "English" is replaced with "Arabic/Mandarin/Japanese/ Thai/ Vietnamese" to represent the respective languages.

The instrument was divided into five categories namely language aptitude (9 items), the language learning difficulty (5 items), learning and communicating strategies ( 7 items), the nature of language learning (6 items) and motivation and expectations (6 items).

\subsection{Data Analysis}

Data from the study was analysed using two statistical procedures appropriate in responding to research questions, namely descriptive statistics using percentage and one way ANOVA. Although the instrument was made up of a 5-likert scale, during data analysis the scales were collapsed into 3 (disagree, neutral, agree) for the purpose of clarity.

The following research questions are formulated:

RQ1: What beliefs do students of foreign languages hold about language learning?

RQ2: Is there any significant difference in the beliefs of students about learning foreign languages (BALLI scores) among the different languages?

\subsection{Sample}

All semester 5 diploma in TESL students at a public university in the east coast of Malaysia were recruited as respondents for this study. At the time of the data collection, the students were currently enrolled in compulsory foreign language classes such as Japanese, Arabic and Thai. However, out of 89 questionnaires returned, only 79 were usable. Some questionnaires had to be rejected because of incomplete responses.

\subsection{Research Design}

The study employs a cross sectional survey design to describe the trends in the data. This type of design is suitable in gathering information with regard to attitudes and practices (Creswell, 2008)

\section{Results}

Demographic profile of the respondents is presented in Table 2. 
Table 2. Demographic background of the respondents

\begin{tabular}{llll}
\hline category & & $\mathrm{N}$ & $\%$ \\
\hline gender & male & 13 & 16.5 \\
& female & 66 & 83.5 \\
foreign language & & & \\
& Mandarin & 30 & 38.0 \\
& Japanese & 22 & 27.8 \\
& Arabic & 17 & 21.5 \\
& Thai & 10 & 12.7 \\
\hline
\end{tabular}

The respondents were mostly female $(84 \%)$ as teaching programme such as TESL was more attractive to females. Of the four foreign language classes, Mandarin was the most popular (38\%) while Thai was the least popular $(13 \%)$ among students in TESL.

In addition, reliability analysis was performed in order to ascertain the reliability of the BALLI instrument, using the Cronbach alpha coefficient. In the present study, the instrument was found to have good internal consistency, as the Cronbach alpha coefficient was reported to be at .73 which according to DeVellis (2003), is considered acceptable.

The subsequent section presents the findings for the two research questions posed.

\subsection{RQ 1: General Beliefs about Foreign Language Learning}

Descriptive analysis using percentage was calculated to determine students' overall beliefs in all the four foreign languages enrolled. The data are presented according to the beliefs' components.

Table 3. Students' beliefs based on language aptitude (in \%)

\begin{tabular}{lllll}
\hline No & Statement & Disagree & Neutral & Agree \\
\hline 1. & It is easier for children than adults to learn a foreign language. & 3 & 11 & 87 \\
2. & Some people have a special ability for learning foreign languages. & 5 & 16 & 84 \\
6. & Malaysians are good at learning foreign languages. & 8 & 64 & 28 \\
10. & It is easier for someone who already speaks a foreign language to learn another one. & 27 & 19 & 55 \\
11 & People who are good at mathematics or science are not good at learning foreign & 55 & 35 & 11 \\
& languages & & \\
16. & I have a special ability for learning foreign languages. & 39 & 37 & 24 \\
19. & Women are better than men at learning foreign languages. & 28 & 53 & 19 \\
30. & People who speak more than one language are very intelligent. & 0 & 7 & 93 \\
33. & Everyone can learn to speak a foreign language. & 1 & 7 & 92 \\
\hline
\end{tabular}

Table 3 presents the results for the component of language aptitude beliefs. This category measures students' belief regarding specific abilities for foreign language learning. A great majority of students agree to most items in this category. An overwhelming number (93\%) believes that people who speak more than one language are very intelligent. Similarly, a large proportion of the respondents (92\%) agree that everyone can learn to speak a foreign language. On the contrary, surprisingly, only a small percentage (24\%) agree with almost the same statement $I$ have a special ability for learning foreign languages. This shows that students do not have the confidence in their own ability to learn although they believe that everybody has the ability to do that.

Table 4. Students' beliefs based on language learning motivation and expectation (in \%)

\begin{tabular}{|c|c|c|c|c|}
\hline No & Statement & Disagree & Neutral & Agree \\
\hline 5. & I believe that I will learn to speak this language very well. & 8 & 43 & 49 \\
\hline 20. & Malaysians feel that it is important to speak this language. & 43 & 37 & 20 \\
\hline 24. & $\begin{array}{l}\text { I would like to learn this language.so that I can get to know native speakers } \\
\text { better and their cultures. }\end{array}$ & 5 & 20 & 75 \\
\hline 29. & If I learn this language very well, I will have better opportunities for a good job. & 3 & 20 & 77 \\
\hline 31. & I want to learn to speak this language well. & 0 & 3 & 97 \\
\hline 32. & I would like to have friends who speak this language as a native language. & 4 & 12 & 84 \\
\hline
\end{tabular}


The second component of BALLI is beliefs about language learning motivation and expectation. The results can be seen in Table 4. A great majority of students responded positively towards most items in this category. It can be seen that a large majority of students associate learning foreign languages with knowing native speakers and their cultures better (75\%) and having opportunities for a good job (77\%). This indicates that students are highly motivated both intrinsically and extrinsically to learn the language.

However, one particular item (item 20-Malaysians feel that it is important to speak this language) received a very low agreement (20\%). This shows that students do not think that the people in the country value the ability to speak foreign languages much. This is partly because some languages are not that useful in the Malaysian context.

Table 5. Students' beliefs about the nature of language learning (in \%)

\begin{tabular}{|c|c|c|c|c|}
\hline No & Statement & Disagree & Neutral & Agree \\
\hline 8. & $\begin{array}{l}\text { It is important to know about the foreign language-speaking cultures in order } \\
\text { to speak this language. }\end{array}$ & 12 & 33 & 55 \\
\hline 12. & It is best to learn this language in its language-speaking country. & 15 & 15 & 71 \\
\hline 17. & $\begin{array}{l}\text { The most important part of learning a foreign language is learning vocabulary } \\
\text { words. }\end{array}$ & 1 & 5 & 93 \\
\hline 23. & $\begin{array}{l}\text { The most important part of learning a foreign language is learning the } \\
\text { grammar. }\end{array}$ & 12 & 23 & 65 \\
\hline 27. & Learning a foreign language is different than learning other academic subjects. & 12 & 15 & 73 \\
\hline 28. & $\begin{array}{l}\text { The most important part of learning English is learning how to translate from } \\
\text { my native language to English or from English to my native language. }\end{array}$ & 7 & 12 & 81 \\
\hline
\end{tabular}

The next component deals with beliefs about the nature of language learning. Results for this category are presented in Table 5. All the items in this category received positive responses from the students. Responses to item 17 and 23 with regards to learning vocabulary and grammar were both $93 \%$ and $65 \%$ respectively. Furthermore the high rate of agreement is seen in item 28 pertaining to the use of translation in learning (81\%). This overwhelming agreement indicates that students have certain beliefs regarding how best to learn a language. The results concur with Altan's (2006) study. This type of beliefs will lead learners into investing their time learning grammar rules, vocabulary, and translating text or thoughts. This is not surprising as this traditional method of learning (Grammar Translation Method) is still very popular in Malaysian schools when studying English although both the students and teachers are aware of the importance of communicative activities in enhancing language proficiency.

Table 6. Students' beliefs about difficulty of language learning (in \%)

\begin{tabular}{|c|c|c|c|c|}
\hline No & Statement & Disagree & Neutral & Agree \\
\hline 3. & Some languages are easier to learn than others. & 5 & 19 & 76 \\
\hline 4. & This language is... language & 39 & 55 & 7 \\
\hline 15. & $\begin{array}{l}\text { If someone spent one hour a day learning a language, it will take them...... } \\
\text { years to speak the language very well }\end{array}$ & 79 & 15 & 7 \\
\hline 25. & It is easier to speak than understand a foreign language. & 33 & 45 & 21 \\
\hline 34. & It is easier to read and write this language than to speak and understand it. & 21 & 25 & 48 \\
\hline
\end{tabular}

With regard to beliefs on difficulty of language learning, 5 items are used to measure it. As shown in Table 6, a large proportion of language learners $(76 \%)$ agree that some languages are easier than others. At the same time, for item 4 perceived difficulty of the foreign language they were enrolled, only a small percentage (7\%) think that the language they are learning is easy, while a large majority of them (79\%) believes that it ranges from difficult to very difficult. These results lend their support to the notion of language learning difficulty hierarchy. Response to item 15 pertaining to duration needed to master a language, a great majority (79\%) think it can be done within 2 years. Taken these 2 responses together, it indicates that although they believe the languages learned are difficult, they set unrealistic time frame to master them. These mismatched expectations tend to make students disappointed if they don't achieve the target. The results echoed the ones found by Horwitz (1988). 
Table 7. Students' beliefs about language learning and communicative strategies (in \%)

\begin{tabular}{|c|c|c|c|c|}
\hline No & Statement & Disagree & Neutral & Agree \\
\hline 7. & It is important to speak this language with an excellent pronunciation. & 5 & 9 & 85 \\
\hline 9. & You shouldn’t say anything until you can say it correctly. & 62 & 20 & 17 \\
\hline 13. & I enjoy practicing English with the native English speakers I meet. & 15 & 40 & 45 \\
\hline 14. & It's o.k. to guess if you don't know a word in English. & 13 & 17 & 65 \\
\hline 18. & It is important to repeat and practice a lot. & 1 & 23 & 76 \\
\hline 21. & I feel timid speaking with other people. & 32 & 31 & 37 \\
\hline 22. & $\begin{array}{l}\text { If beginning students are permitted to make errors, it will be difficult for them } \\
\text { to speak correctly later on. }\end{array}$ & 52 & 25 & 23 \\
\hline 26. & It is important to practice with cassettes or tapes. & 16 & 48 & 36 \\
\hline
\end{tabular}

The last component, beliefs about language learning and communicative strategies assesses students' perspective on the use of various strategies in enhancing learning. The results are presented in Table 7. It is interesting to note that, a majority of the learners (62\%) reported disagreement with item 9 You shouldn't say anything until you can say it correctly although they agree (85\%) with item 7 that it is important to have good pronunciation. Similarly, item 14 (ok to guess), and item18 (the importance of practicing) received high agreement (65\% and $76 \%)$ respectively. In other words, the fact that students believe in having good pronunciation does not deter them from trying to use the language. These are indeed characteristics of good language learners as highlighted by Stern (1993).

\subsection{RQ2: Is There a Statistically Significant Difference among the Beliefs of TESL Students Enrolling in Different Foreign Languages?}

In order to investigate the impact of foreign languages enrolled on the levels of beliefs as measured by the instrument BALLI, a one-way between-group ANOVA was conducted. Subjects were divided into four groups based on the foreign language classes enrolled (Group 1: Mandarin, Group 2: Arabic, group 3: Japanese, and group 4: Thai).

Results for this analysis are presented in Table 8 . The results showed a statistically significant difference at $\mathrm{p}<.05$ in the BALLI scores for the four language groups: $\mathrm{F}(3,71)=4.238, \mathrm{p}=.008$.

Table 8. Results of ANOVA by foreign language groups

\begin{tabular}{lllllll}
\hline Component & Language group & Mean & SD & df & F & Sig \\
\hline BALLI scores & Mandarin & 3.59 & .28 & 3.71 & 4.238 & $.008^{*}$ \\
& Arabic & 3.42 & .24 & & & \\
& Japanese & 3.65 & .26 & & & \\
& Thai & 3.31 & .30 & & & \\
\hline
\end{tabular}

Note. *sig at $\mathrm{p}=.05$.

As the results indicate significant p-value, post-hoc comparison using the Scheffe test was used in order to find out where the differences lie. The post hoc for the BALLI scores, indicates the mean score for the learners of Japanese $(\mathrm{M}=3.65, \mathrm{SD}=.26)$ was statistically different from the Thai group $(\mathrm{M}=3.31, \mathrm{SD}=.30)$. Similarly, Japanese group ( $\mathrm{M}=3.65, \mathrm{SD}=.26)$ differs statistically from Arabic group $(\mathrm{M}=3.42, \mathrm{SD}=.24)$. Other groups, however did not significantly differ from one another. The effect size which was calculated using eta square was 0.15 which is considered small (Cohen, 1988). This indicates that although the difference is significant, the actual difference in the mean score is rather small.

In other words, these results suggest that the foreign languages do have an impact on the beliefs about the language learning. Learners of Japanese tend to have more positive perspectives of language learning process than other foreign languages. The results contradicted previous findings (Altan, 2006) which discovered similarity of beliefs among the different foreign languages. Conversely, it supports the findings from Ariogula, Cigdem \& Onursal's study (2009) which found that the beliefs differ from language to language. Learners of French were found to be more positive than German and English.

\section{Conclusion and Recommendation}

The study set out to explore the beliefs of TESL students about learning foreign languages in UniSZA. Two research questions were formulated. Based on the first research question, it can conclude that students have a 
range set of beliefs. Some are realistic while others are slightly far-fetched. If the beliefs are realistic, then they are facilitative to the learning process, thus helping students to shape their learning in the right direction. These positive beliefs coupled with positive teacher, conducive environment and motivated learner will produce amazing results in language learning (Mihat, 2016). On the other hand, if the beliefs are unrealistic, they could be detrimental to their language performance thus affecting learning negatively. Similarly, compared to previous studies on foreign languages (Horwitz, 1988; Ariogula, Cigdem, \& Onursal, 2009), some aspects of the beliefs are the same across the languages whereas others are different. This shows that some beliefs are universal regardless of the languages learnt. On the other hand, other beliefs are peculiar to a particular language only. Therefore, in order to be successful in acquiring a language, they must be made aware of the difference between these two categories of beliefs.

Research question 2, on the other hand was interested in comparing the beliefs among the languages. It is interesting to discover that the beliefs held are influenced by the foreign languages enrolled. Learners of Japanese seem to hold more positive beliefs than Arabic and Thai learners. Furthermore, the mean scores for Mandarin and Japanese were higher than two other foreign languages. This could be due to the fact that these two languages are seen as important foreign languages in Malaysia for economic reasons.

Hence, in order to encourage more Malaysians to learn foreign languages and subsequently become good at it, one of the things that can be done is to change their mindset regarding language learning. They have to be made aware that some beliefs are facilitative while others are detrimental to their learning.

\section{Implications and Limitations}

The study has a number of pedagogical implications for both language teachers and learners. One is that, it gives teachers some insights on the preparation of classroom materials as teachers are aware of what students' expectations of the class are. Another is that, some of the beliefs held by the students were proven to be detrimental to their learning. Thus, teachers have the obligations to correct the misleading perspectives to prevent students from getting unmotivated and losing interests in the class. Likewise, students must be willing to change their perspectives with regard to learning a foreign language. Failing which, language learning becomes a burden to them.

Results from the study should be viewed in light of their limitations. One such limitation is the unequal distribution of respondents in each language category. Some languages have more learners than the others. Ideally, for ANOVA to provide better and more accurate results there should be almost equal number of respondents in each group. However, since the study was based on intact class, the issue was beyond the researcher's control. Another is that, the study was conducted in the middle of semester when learning has already taken place. As Horwitz's (1988) recommends, assessing students' beliefs on language learning should be done early in the semester for better results. Thus future studies conducted should take the above limitations into account.

\section{References}

Altan, M. X. (2006). Beliefs about Language Learning of Foreign Language- Major University Students. Australian Journal of Teacher Education, 31(2). http://dx.doi.org/10.14221/ajte.2006v31n2.5

American Psychological Association. (1972). Ethical standards of psychologists. Washington, DC: American Psychological Association.

Ariogul, S., Cigdem, D., \& Onursal, I. (2009). Foreign language learners' beliefs about language learning: a studyon Turkish university students. Procedia Social and Behavioral Sciences, 1, 1500-1506. https://doi.org/10.1016/j.sbspro.2009.01.265

Bernat, E. (2006). Assessing EAP learners' beliefs about language learning in the Australian context. Asian EFL Journal, 8(2), 202-227. Retrieved from http://www.asian-efl-journal.com/June_06_eb.phb

Brown, H. D. (2000). Principles of language learning and teaching. New York: Addison-Wesley Longman.

Creswell, J. (2008). Educational research: Planning, Conducting, and evaluating Quantitative and Qualitative Research. Pearson: New Jersey.

Horwitz, E. K. (1987). Surveying students' beliefs about language learning. In A. L. Wenden \& J. Rubin (Eds.), Learner strategies in language learning (pp. 119-129). London: Prentice Hall.

Horwitz, E. K. (1988). The beliefs about language learning of beginning university foreign language students. The Modern Language Journal, 72, 182-193. https://doi.org/10.1111/j.1540-4781.1988.tb04190.x 
Mihat, W. (2016). "Bertehtuh" English: The Experience of a Temiar Girl in Acquiring English. Journal of Nusantara Studies, 1(2) 25-37.

Ministry of Education, Malaysia. (2013). National Education Blueprint 2013-2025.

Ministry of Higher Education, Malaysia. (2007). National Higher Education Strategic Plan beyond 2020.

Nikitina, L., \& Furuoka, F. (2007). Beliefs about language learning: A comparison between novice and intermediate level students learning Russian at a Malaysian university. The Linguistics Journal, 2(1), 7-27.

Pajares (2002). Overview of social cognitive theory and of self-efficacy. Retrieved from http://www.emory.edu/EDUCATION/mfp/eff.html

Peacock, M. (2001). Pre service ESL teachers' beliefs about second language learning: A longitudinal study. System, 29, 177-195. https://doi.org/10.1016/S0346-251X(01)00010-0

Stern, H. H. (1983). Fundamental Concepts of Language Teaching. Oxford: Oxford University Press.

Weideman, A., \& Lepota, B. (2002). Our ways of learning language. SAALT Journal for Language Teaching, 36(3-4), 206-219.

Wong, M. S. L. (2010). Beliefs about Language Learning: A Study of Malaysian Pre-Service Teachers. RELC Journal, 41(2), 123-136. https://doi.org/10.1177/0033688210373124

\section{Copyrights}

Copyright for this article is retained by the author(s), with first publication rights granted to the journal.

This is an open-access article distributed under the terms and conditions of the Creative Commons Attribution license (http://creativecommons.org/licenses/by/4.0/). 